\title{
Investigating therapeutic usage of combinedticagrelor and aspirin through solid-state and analytical studies
}

\author{
Hassane Sadou Yayée,b,1, Ivo B. Rietveld ${ }^{c, d}$, Maria Barrio ${ }^{e, f}$, Philippe-Henri Secrétana, \\ Antoine Faucheron ${ }^{\mathrm{b}}$, Maher Karoui $^{\mathrm{a}}$, Patrick Tilleul ${ }^{\mathrm{b}}$, NajetYagoubi ${ }^{\mathrm{a}}$, Bernard Do ${ }^{\mathrm{a}, \mathrm{g}}$ \\ a Université Paris Sud, UFR de Pharmacie, UA 401 « Matériaux et Santé ». 5, rue Jean Baptiste Clément, 92296 \\ Châtenay-Malabry, France
}

${ }^{\mathrm{b}}$ Assistance Publique-Hôpitaux de Paris, Groupe Hospitalier Pitié-Salpêtrière, Department of Pharmacy,47-83 Boulevard de l'Hôpital, 75013 Paris, France

c University of Paris-Descartes, Faculty of Pharmacy, Laboratory of Physical Chemistry, 4 avenue de l'Observatoire, 75006 Paris, France

${ }^{\text {d} N o r m a n d i e ~ U n i v e r s i t e ́, ~ L a b o r a t o i r e ~ S M S ~-~ E A ~ 3233, ~ U n i v e r s i t e ́ ~ d e ~ R o u e n, ~ F ~} 76821$ Mont Saint Aignan, France

eGrup de Caracterització de Materials, Departament de Física, EEBE, UniversitatPolitècnica de Catalunya, Campus Diagonal-Besòs, Av. Eduard Maristany 10-14, 08019 Barcelona, Catalonia, Spain

fBarcelona Research Center in Multiscale Science and Engineering, Av. Eduard Maristany, 10-14, Barcelona 08019, Spain

${ }^{\mathrm{g}}$ Assistance Publique-Hôpitaux de Paris, Groupe hospitalier Henri Mondor, Department of Pharmacy, 51 Avenue du Maréchal de Lattre de Tassigny, 94010 Créteil, France

${ }^{1}$ Correspondence to:

Dr H. SADOU YAYE, Université Paris Sud, UFR de Pharmacie, 5, rue Jean Baptiste Clément, 92296 Châtenay-Malabry.

Email address: hassane.sadou-yaye@aphp.fr

Tel: +33622206246

Fax: +33142178261 


\section{ABSTRACT:}

The mainstay treatment for patients with acute coronary syndrome is an oral route dual antiplatelet therapy with a P2Y12-receptor antagonist and Aspirin (ASA).To improve patient adherence to such treatments, combination therapies (polypill) are envisioned. Physicochemical solid-state studies have been carried out to develop a preformulationstrategy of ASA with the P2Y12-receptor antagonistticagrelor (TIC). The investigations were carried out using differential scanning calorimetry,liquid chromatography - high resolution - multistage mass spectrometry (LC-HR-MS ${ }^{n}$ ) and as complementary techniques Fourier transform infrared measurements and thermogravimetric analysis. A simple eutectic transition at $98^{\circ} \mathrm{C}$ with a mole fraction for the eutectic liquid of 0.457 has been observed and the mixing of ASA and TIC molecules in each other's crystal structures appears to be limited. No cocrystals of TIC and ASA have been found. The appearance of the eutectic liquid was linked with a clear onset of chemical instability of the two pharmaceuticals. The decomposition mechanism in the liquid phase involves prior decomposition of ASA, whose residues react with well-identified TIC interaction sites. Seven interaction products were observed by LC-HR-MS ${ }^{n}$ linked to corresponding degradation products. The most important degradation pathway is N-dealkylation. In conclusion, polypills of ASA and TIC are a viable approach, but the decomposition of ASA should be avoided by eliminating high temperatures and high humidity.

\section{Introduction}

Cardiovascular diseases, and in particular acute coronary syndrome (ACS), remain the most serious life-threatening diseases [1].Dual antiplatelet therapy, consisting of aspirin (ASA) and 
a P2Y12-receptor antagonist, is the mainstay treatment for patients with ACS. A complicating factor of a dual therapy is the necessity for patients to take multiple drugs, which diminishes patient adherence to the treatment. To avoid this kind of problems and to improve on the necessary doses of the different pharmaceuticals in a dual treatment, combination therapies (polypill) may be a solution.

However, the combined drug introduces the problem of possible interactions between the active ingredients. This may have an influence on their bioavailability, render the formulation inactive, or even toxic, as issues with drug-drug or drug-excipient interactions have been widely described in the literature [2-6]. Chemical instabilities due to interactions can take the form of oxidation, reduction or hydrolysis[2, 3], and drug substances may even covalently bind to each other [4]. Physical incompatibility may include a modification of the individual solubilities or the formation of a eutectic liquid, which will modify the formulation and also accelerate degradation of the pharmaceuticals $[5,6]$. It is therefore essential that combinations of active pharmaceutical ingredients are studied beforehand. In particular, the chemical and physical behaviour of the mixtures is of importance, as they may be the first to indicate what will happen to the final mixed drug product. The outcome can then be used in the preformulation strategy to stabilize the drug.

In the present paper, the chemical and physical stability of mixtures of ASA with the P2Y12receptor antagonistticagrelor (TIC) will be studied to support the development of a combination therapy with these two active ingredients. The dosage quantities of TIC are rather well defined at $90 \mathrm{mg}$ per tablet [7]. In the case of ASA, it is well known that high doses are associated with higher rates of major bleeding in patients [8]. A large systematic review on the efficacy of ASA to avoid blood clots has demonstrated that there are no differences in clinical outcome between low or high doses of ASA in the medical treatment following surgical stent insertions [8], thus for a combination therapy an effective ASA dosage quantity can be kept at a relatively low concentration. A double blind clinical trial evaluation of the pharmacokinetics and pharmacodynamics of ticagrelor co-administered 
with $300 \mathrm{mg} \mathrm{qd}$. ofaspirin in healthy volunteers has demonstrated that simultaneous administration of TIC and ASA does not affect the medical treatment negatively [9].

According to the literature, ASA melts around $138{ }^{\circ} \mathrm{C}$ with amelting enthalpy of $185 \mathrm{~J} \mathrm{~g}^{-}$ ${ }^{1}[10,11]$. It is also well known that ASA rapidly decomposes in the presence of water, while forming acetic acid and salicylic acid [12]. In the case of TIC, a single patent exists describing four polymorphs called I, II, III and IV melting at 128, 135, 139 and $150{ }^{\circ} \mathrm{C}$ respectively [13]. Previously, the chemical behaviour of TIC under several stress conditions has been investigated, which resulted in the elucidation of nine main degradation products formed through oxidation, S-dealkylation and $\mathrm{N}$-dealkylation mechanisms [14]. Taking into account the physical and chemical properties of the pure compounds, mixtures of ASA and TIC will be investigated using differential scanning calorimetry (DSC) andliquid chromatography - high resolution - multistage mass spectrometry (LC-HR-MS ${ }^{n}$ ) and as complementary techniques Fourier Transform Infrared measurements (FTIR) and thermogravimetric analysis (TGA).

\section{Materials and methods}

\section{Materials}

Ticagrelor of a purity greater than $98 \%$ was obtained from Interchim ${ }^{\circledR}$ (Montluçon, France). Acetylsalicylic acid (purity: $99.5 \%$ ) was purchased from Cooper (Melun, France). Analytical grade acetonitrile was provided by Sigma-Aldrich (St Quentin-Fallavier, France). Ultrapure water from Q-Pod Milli-Q system (Millipore, Molsheim, France) was used for dissolution, dilution, and as a component of the mobile phase.

\section{Solid-state stress testing}


TIC and ASA substances were dried at $80^{\circ} \mathrm{C}$ in an oven for 24 hours, then mixed (1:1molar ratio) by gentle grinding using a mortar and a pestle for 5 minutes. $50 \mathrm{mg}$ of the two APIs and theirmixture were prepared in triplicate, placed in a calibrated hot-air oven at $80{ }^{\circ} \mathrm{C}$, and at $100{ }^{\circ} \mathrm{C}$ and removed after either 1 day or 3 days of exposure.

In parallel, kinetic studies were performed.Samples of about $10 \mathrm{mg}$ of TIC-ASA mixtures were preparedin triplicate and placed in ovensat $25,40,60,70,80$, and $90{ }^{\circ} \mathrm{C}\left( \pm 1{ }^{\circ} \mathrm{C}\right)$. The samples were removed at $0,1,2,3,7,14,21$, and 28 days and analysed by HPLC. Concurrently, TIC, ASA and TIC-ASA mixture control samples stored at $25^{\circ} \mathrm{Cfor}$ one year have been testedfor degradation products.

\section{Analytical Methods}

\section{Differential scanning calorimetry}

DSC experiments were performed using a Q1000 (TA Instruments, USA) heat-flux calorimeter. It was calibrated before use with high purity indium $\left(\mathrm{T}_{\text {fus }}=156.60{ }^{\circ} \mathrm{C}\right)$ and tin $\left(\mathrm{T}_{\text {fus }}=231.91{ }^{\circ} \mathrm{C}\right)$ standards. Drug mixture samples of approx. $1.5-4 \mathrm{mg}$ were scanned in sealed aluminum pans at a rate of $10 \mathrm{~K} \mathrm{~min}^{-1}$, from 30 to $160{ }^{\circ} \mathrm{C}$, in an inert $\mathrm{N}_{2}$ atmosphere with a purge flow rate of $50 \mathrm{~cm}^{3} \mathrm{~min}^{-1}$.

For temperature - composition diagrams, binary physical mixtures with TIC-ASA concentrations of (mol fraction TIC): $1.00,0.95,0.90,0.80,0.70,0.60,0.50,0.40,0.30,0.20$, $0.10,0.05$, and 0.00 were prepared by gentle mixing and grinding of the two compounds using a mortar and a pestle for 5 min,then the melting behaviour of the samples were assessed by DSC. Subsequently, heating-cooling cycles of selected samples were carried out. Additionally, the crucibles were retrieved, opened, dissolved in $1 \mathrm{ml}$ of acetonitrile, sonicated for $10 \mathrm{~min}$, and analysed by LC-HR-MS ${ }^{n}$. 


\section{X-ray powder diffraction}

A Debye-Scherrer optics was used with an INEL powder diffractometer equipped with a cylindrical position-sensitive detector (CPS120) containing 4096 channels $\left(0.029^{\circ} 2 \theta\right.$ angular step) and monochromatic $\mathrm{Cu} \mathrm{Ka}_{1}(\lambda=1.54061 \AA)$ radiation. Slightly ground specimens were introduced in a Lindemann capillary $(0.5 \mathrm{~mm}$ diameter) rotating perpendicularly to the X-ray beam during the experiments to improve the average over the crystallite orientations.

\section{Thermal gravimetric analysis}

TG measurements were carried out using a TA instruments Q500 thermogravimetric analyzer (TGA) equipped with a precision thermobalance $(0.1 \mu \mathrm{g})$. The weighted samples (3$8 \mathrm{mg}$ ) were heated from $25{ }^{\circ} \mathrm{C}$ to $600{ }^{\circ} \mathrm{C}$. Heating runs were carried out under nitrogen atmosphere at three heating rates: 5,10 and $20 \mathrm{~K} \mathrm{~min}^{-1}$.

\section{Fourier Transform Infrared measurements}

FTIR was used to assess the modification of the molecular environment of the APIs induced in the physical mixture(0.30 mole fractionTIC). The experiments were performed on a PerkinElmer Spectrum BX FT-IR system based on diffuse reflectance sampling accessories with FT-IR Spectrum v2.00 software. The spectra of the APIs, their mixtures and the corresponding stressed samples were recorded at room temperature in the wavenumber range of $400-4000 \mathrm{~cm}^{-1}$ using $\mathrm{KBr}$ pellets.

\section{High Pressure Liquid Chromatography}

A Dionex Ultimate 3000 LC system (DIONEX, Les Ulis, France) was used to separate the APIs and their degradation/interaction products from the stress samples and the DSC 
crucibles. The system consisted of a quaternary pump, a degasser, a thermostatedautosampler with a $200 \mu \mathrm{L}$-injection syringe, and a thermostated column compartment. A C18 (Phenomenex $\left.{ }^{\circledR}\right)(150 \mathrm{~mm} \times 4,6 \mathrm{~mm}, 4 \mu \mathrm{m})$ column set at $25{ }^{\circ} \mathrm{C}$ was used. The optimized LC parameters include the mobile phase composition (phase A: acetonitrile, phase B: water) set in a gradient method (A $20 \% \mathrm{v} / \mathrm{v}$ from 0 to $5 \mathrm{~min}$; A $20 \%$ to $60 \% \mathrm{v} / \mathrm{v}$ from 5 to $7 \mathrm{~min}$; A $60 \rightarrow 80 \% \mathrm{v} / \mathrm{v}$ from 15 to $17 \mathrm{~min} ; \mathrm{A} 80 \rightarrow 20 \% \mathrm{v} / \mathrm{v}$ from 17 to 20 min and $A 20 \% v / v$ till $25 \mathrm{~min})$. The flow-rate was set at $1 \mathrm{~mL} \mathrm{~min}{ }^{-1}$.

\section{An LC-high-resolution multistage mass spectrometry}

LC-HR-MS ${ }^{n}$ was used to elucidate the structures of the decomposition products following DSC and stress tests. It was performed by coupling a Dionex® LC system to an electrospray (ESI)-LTQ-OrbitrapVelos Pro system, which comprises a double linear trap and an orbital trap (Thermo Fisher Scientific, CA, USA). Analyses were carried out in positive and negative ion mode for TIC and ASA respectively, under the following conditions: (a) the source voltage was set at $3.4 \mathrm{kV}$; (b) the temperatures were fixed at $53^{\circ} \mathrm{C}$ (source) and $300{ }^{\circ} \mathrm{C}$ (capillary); (c) S-Lens was set at $60 \%$. Acquisition in full scan mode over the mass range of $50-600 \mathrm{Da}$ was performed for the detection of the degradation products. 30-40 \% CEL were set for highresolution fragmentation studies. The MS data were processed using Xcalibur $^{\circledR}$ software (version 2.2 SP 1.48).

\section{Results and discussion}

\subsection{Physical stability in the solid mixtures of TIC and ASA}

For the pure compounds the following melting data were found: TIC led to a $\mathrm{T}_{\text {onset }}=136.2$ $\pm 1.9{ }^{\circ} \mathrm{C}$ and $\mathrm{a} \Delta \mathrm{H}_{\text {fus }}=81 \pm 5 \mathrm{~J} \mathrm{~g}^{-1}$ and ASA melts at $138.1 \pm 2.5^{\circ} \mathrm{C}$ with a $\Delta \mathrm{H}_{\text {fus }}$ at $184.5 \pm 13.1$ $\mathrm{J} \mathrm{g}^{-1}$. The melting data and the X-Ray pattern (Figure S1) of aspirin sample used were found to be consistent with the aspirin form I $[10,11,15]$. The melting point of TIC in combination 
with an X-ray diffraction pattern (Figure S2)for verification indicates that the TIC sample contained pure form II according to the information provided in the patent [13].

Physical mixtures were prepared by gently grinding different mole fractions of TIC and ASA as indicated in the experimental section. The mixtures were subsequently subjected to DSC measurements in a closed capsule by heating the samples at a rate of $10 \mathrm{~K} \mathrm{~min}^{-1}$ from $30{ }^{\circ} \mathrm{C}$ up to $160{ }^{\circ} \mathrm{C}$. The DSC curves exhibited two endothermic peaks indicative of the occurrence of a eutectic and a liquidustransition (see Figure 1a) [16-18]. The onset temperature of the eutectic peak, $98^{\circ} \mathrm{C}$, and the peak maximum of the liquidus peak were used to plot the temperature-composition TIC-ASA phase diagram (Figure 1b). The dependence of the eutectic molar enthalpy with the mole fraction of TIC, the Tammann plot, was used to estimate the eutectic composition (see Figure 1c) $[19,20]$. The ASA rich side of the Tammann plot led to the following equation: $\Delta \mathrm{H}_{\text {eutectic }}(\mathrm{x})=62,249 \cdot \mathrm{x}$ and the TIC rich side led to the equation $\Delta \mathrm{H}_{\text {eutectic }}(\mathrm{x})=-52,298 \cdot \mathrm{x}+52398$. With these two expressions a eutectic mole fraction of 0.457 was calculated. Considering the Tammann plot and the T-x phase diagram, the TIC-ASA system exhibits a simple eutectic transition at $98^{\circ} \mathrm{C}$ with a mole fraction for the liquid of 0.457 (Fig. 1b-c).

A eutectic equilibrium consists of an equilibrium between three phases and can be written as 
concentration of one of the components is sufficiently low that it can completely 'dissolve' in the crystal structure of the other component, thus when only a single solid solution is present in the system, the eutectic transition will not be observed, because the single solid phase will have a different melting behaviour and the eutectic heat effect will be equal to zero. The intersection of the Tammann plot - the eutectic enthalpy effect plotted against the binary composition - with the composition axis will therefore provide an indication of the extent of the solid solution in terms of concentration. In the present case, the enthalpy effect of the eutectic transition appears to extend to the pure compositions as the Tammann plot intersects the composition axis at 0 and at 1 mole fraction. Therefore, it can be concluded that the extent of the solid solutions, i.e. the mixing of ASA in solid TIC and of TIC in solid ASA, is probably limited in this system. Moreover, considering the observed eutectic transition, it can be concluded that interactions in the form of binary compounds (or cocrystals) seem to be absent in this system.

Figure 1: Ticagrelor - Aspirin solid-state behaviour: a) typical DSC curves; b) temperaturecomposition phase diagram with eutectic behaviour (mole fraction of Ticagrelor indicated), and c) Tammann's plot of the eutectic transition.

\subsection{Chemical stability in mixtures with TIC and ASA}

\subsubsection{Thermal stress testing}

It can be seen in table 1 that the physical appearance of pure TIC and of pure ASA kept at $80^{\circ} \mathrm{C}$ and $100^{\circ} \mathrm{C}$ does not change. A mixture of ASA and TIC (1:1 molar ratio) retains the same appearance for 1 day at $80^{\circ} \mathrm{C}$. However, the powder becomes yellowish when left at $80^{\circ} \mathrm{C}$ for three days. In the case of $100^{\circ} \mathrm{C}$, the change in colour is observed within one day. 
It is clear from the preceding results that chemical interactions occur in the mixtures of TIC and ASA. It should be kept in mind that at $80^{\circ} \mathrm{C}$ the mixture will be solid, whereas at $100^{\circ} \mathrm{C}$ part of the mixture will have become liquid, as the eutectic temperature has been passed.

The samples have been investigated by LC-HR-MS ${ }^{n}$. The fragmentation pattern of TIC was obtained in a previous publication [14]. Those results will be used to analyse the interaction and degradation products in the present mixture with TIC and ASA. In the LC-HR-MS ${ }^{n}$ results, the interaction products (IPS) are defined as those stemming from the entire TIC molecule attached to other molecular moieties in particular from ASA. In addition, degradation products (DPs) are defined as those with a smaller mass stemming from TIC directly or from one of the IPs. Once an IP or a DP has been identified, the elemental composition is deduced and the mass error is calculated for verification (see Table 2).

Table 1: Physical appearance of Ticagrelor, Aspirin, and their mixtures (1:1 molar ratio)under thermal stress conditions

Table 2: $\mathrm{LC}-\mathrm{HR}-\mathrm{MS}^{\mathrm{n}}$ results: Retention time and accurate mass of Ticagrelor - Aspirin interactions products and their corresponding $\mathrm{N}$-dealkylation degradation products (see text).

\section{Pure APIs}

LC-HR-MS $^{n}$ did not reveal any degradation product in the case of the pure active pharmaceutical ingredients that were kept for one day at $80^{\circ} \mathrm{C}$. It has been verified by LC$\mathrm{HR}^{-M S^{n}}$ that heating samples of pure TIC in the DSC up to $160^{\circ} \mathrm{C}$ did not lead to any degradation products either. These results are consistent with the absence of change in the physical aspect of the pure compounds. For ASA, it is known that it rapidly decomposes into salicylic acid and acetic acid [12] in the liquid phase. 


\section{Degradation kinetics of the mixture}

For each temperature, the remaining TIC-ASAin the mixtures has been plotted as a function of time (Figure 2a,Table S1). The decomposition data has been fitted to zero order expressions, which gave reasonable fits within the limits of precision of the data. The rate constants have been assembled in anArrhenius plot (Figure2b). The activation energy of the observed decomposition reaction of $130 \pm 12 \mathrm{~kJ} \mathrm{~mol}^{-1}$ is similar to the one found by Carstensenet al. for the decomposition of ASA in the presence of water(about $128 \mathrm{~kJ} \mathrm{~mol}^{-1}$ ) even if the reaction rate in the present TIC-ASA mixture is much lower (e.g. in the present mixture at $65^{\circ} \mathrm{C} 0.016$ mole $\% j^{-1}$ is found, whereas Carstensenet al. reported $7.9 j^{-1}$ ) [27]. The rate-limiting step in the decomposition of the TIC-ASA mixture may therefore depend on the decomposition of ASA and the reaction products may subsequently react rapidly with TIC. Extrapolating the Arrhenius equation to $25^{\circ} \mathrm{C}$, one obtains about $1 \%$ of decomposition per year. Tests performed on TIC-ASA samples stored for one year at $25^{\circ} \mathrm{C}$ do not reveal any decomposition products, so the $1 \%$ obtained by the Arrhenius equation might be an upper limit of the decomposition estimate. How the decomposition of ASA affects TIC will be discussed in the next section.

Figure 2: TIC - ASA decomposition kinetics: (a) Concentration in mole $\%$ of remaining TICASA in the stress test samples versus exposure time in days and as a function of temperature $\left({ }^{\circ} \mathrm{C}\right)$ (b) Arrhenius plot of the rate constants obtained by fitting zero order kinetics.

Interaction products observed in the TIC-ASA mixture 
As indicated in Table 2, seven interaction products have been identified named IP1 to IP7. They respectively exhibit masses with 28, 42, 84, 126, 120, 162, and 204 amu higher than that of the TIC molecule. It can be deduced that they respectively represent carbon monoxide-TIC, acetyl-TIC, diacetyl-TIC, triacetyl-TIC, TIC-salicylate, acetyl-TIC-salicylate and diacetyl-TIC-salicylate, as indicated in Table 2.

Four possible TIC interaction sites can be identified, three alcohol functions and a secondary arylamine, as indicated in Figure 3b. A transition in relation to an interaction with the secondary arylamine on the TIC molecule is for example characterised by the neutral loss of the hydroxyethoxycyclopentane-1,2-diol moiety. An interaction with the primary alcohol is characterized by the absence of the neutral loss of ethanal or ethyleneglycol. The presence of the two latter transitions would suggest consequently an interaction with the cyclopentane alcohols. As a result, for the observed products, several LC-separated isomers can be found corresponding to the different interaction combinations on the aforementioned sites (See for example the different peaks for IPs2 and IPs3 in Fig. 3a).

For the product with $\mathrm{m} / \mathrm{z} 565$, the number of IPs was superior to that of the interaction sites, which suggests the formation of stereo-isomeric products. In fact, in the case that the acetylation involves only one of the cyclopentane diols, the formation of a hydrogen bond with the free $\mathrm{OH}$ may yield a hydrogen bond depending on the position of the carbonyl function. This is suggested by the difference in their spectrums, which differ in weight indicative of a water molecule.

Figure 3: a) LC-UV chromatogram of Ticagrelor - Aspirin after thermolysis at $80^{\circ} \mathrm{C}$ for $24 \mathrm{~h}$; b) Possible interactions sites on the TIC molecule 
In our previous study, we have demonstrated that TIC gives rise to the degradation product $\mathrm{m} / \mathrm{z} 371$ by $\mathrm{N}$-dealkylation when it is subjected to $80^{\circ} \mathrm{C}$ in solution [14]. However, the interaction with ASA increased the appearance of this dealkylation productten-fold. In addition, seven degradation products DP1 to DP7 were obtained as a result of the Ndealkylationfrom the interaction products IP1 to IP7. Thus, the arylamineis clearly the main interaction and degradation site of TIC in the presence of ASA.

Besides the formation of acetic acid and salicylic acid, $\mathrm{CO}_{2}$ and/or $\mathrm{CO}$ probably from acetic acid $[28,29]$ could be observed to interact with TIC. This is illustrated in figure 4 , where TIC is presented with an attached carbonyl group and the possible fragmentation pathways.

From the foregoing, it can be concluded that the presence of ASA may affect the chemical stability of TIC in the solid state at elevated temperatures.

Figure 4: Fragmentation pattern of the interaction product IP3 and the related degradation product DP3

\subsubsection{Degradation around the eutectic temperature}

\section{The effect of liquid formation on the degradation process}

It has been shown that the presence of ASA may affect the chemical stability of TIC at elevated temperature. Considering that the eutectic temperature is found around $98^{\circ} \mathrm{C}$, the effect of the formation of a liquid on the chemical stability of TIC in the presence of ASA should be evaluated.

The eutectic mixtures were subjected to a heating-cooling cycle with a heating (cooling) rate of $10{ }^{\circ} \mathrm{C} \mathrm{min}^{-1}$ up to the $\mathrm{T}_{\text {peak }}$ of the eutectic transition $\left(=100{ }^{\circ} \mathrm{C}\right)$ and in certain cases up to 
the end of the liquidus $\left(=130^{\circ} \mathrm{C}\right)$, after which the samples were cooled. The pans were collected and the residues were analysed by LC-HR-MS ${ }^{n}$ in positive mode. As illustrated in Fig.5a, immediate cooling after passing the eutectic temperature generated only one interaction product with $\mathrm{m} / \mathrm{z} 565.2020$, which represents an acetylation product of TIC as has been demonstrated above. By passing the liquidus temperature for a mixture of about 0.3 mole fraction of $\mathrm{TIC}$ at around $120^{\circ} \mathrm{C}$, the intensity of the former interaction product increases significantly along with the appearance of two of its other isomers (Fig.5b). Hence, it is clear that the acetylation of TIC plays an important role in its degradation process. Furthermore, contrary to the solid state, where the chemical interactions only slowly evolved, the liquid state gives almost immediately rise to one of the main degradation products, which next to the increased thermal activation energy, can be ascribed to the increase of the molecular mobility of the two APIs in the liquid [30].

Figure 5: Degradation of Ticagrelor - Aspirin system ( 0.30 mole fraction TIC)in the eutectic liquid (a) and just above the liquidus (b)

\section{Additional evidence by FT-IR}

Several measurements by FT-IR were carried out to investigate to what extent FT-IR can be used to demonstrate the progress of degradation in TIC-ASA mixtures. It can be shown that the pure APIs subjected to $100^{\circ} \mathrm{C}$ for 7 days do not exhibit substantial changes in their FT-IR spectrain comparison with the samples that were kept at room temperature for the same duration nor with the spectra of the samples obtained before heating evidenced by the excellent superposition of the different spectra (see Figure 6a spectra a, b, f, and g).

In the FT-IR spectra of the TIC-ASA physical mixture at TO and $25^{\circ} \mathrm{C}$, the characteristic peaks of the two pure drug substances can be recognized with no other new band present 
(Compare Figure 6a spectra $c$ and $d$ with spectra a and g). This confirmsthat the extent of the solid solutions is limited as observed by DSC.

However, the TIC-ASA physical mixture heated for seven days at $100^{\circ} \mathrm{C}$ revealed a few clear changes (Fig 6a spectrum e, Table S2):

- The absence of the $\mathrm{OH}$ stretching band of TIC at $3365 \mathrm{~cm}^{-1}$, and a significant decrease of the $\mathrm{OH}$ deformation bands (of about 40\%) between 1423 and 1550 $\mathrm{cm}^{-1}$.

- The lack of the stretching vibration band at $1748 \mathrm{~cm}^{-1}$ assigned to the ester carbonyl group of ASA, followed by a significant increase (of about 20\%) of the band of the carbonyl acid, red-shifted from 1748 to $1700 \mathrm{~cm}^{-1}$, and the appearance of a broad shoulder on the right.

- In the fingerprint region from 1100 to $500 \mathrm{~cm}^{-1}$, huge changes in shape and intensity were observed in comparison to the spectra for the mixture at $25^{\circ} \mathrm{C}$.

These results confirm the chemical interactions between TIC and ASA at elevated temperature.It is clear however, that FT-IR is not very sensitive to small chemical changes in the samples.

Figure 6: IR spectra of Ticagrelor, Aspirin and and their mixture ( 0.30 mole fraction TIC) kept under different conditions: a) TIC day $0-25^{\circ} \mathrm{C}$; b) TIC day $7-100^{\circ} \mathrm{C}$; c) TIC-ASA day $0-25^{\circ} \mathrm{C}$; d) TIC-ASA day $7-25^{\circ} \mathrm{C}$; e) TIC-ASA day $7-100^{\circ} \mathrm{C}$; f) ASA day $7-100^{\circ} \mathrm{C}$; g) ASA day $0-25^{\circ} \mathrm{C}$ (The arrows indicate changes in the spectra after storage at high temperature (see discussion text))

\section{Evaporation and its effect on TIC-ASA mixtures}


To further elucidate the degradation process of TIC and ASA, mixtures and the pure compounds have been studied by thermal gravimetric analysis. The TG curves of ASA and TIC under nitrogen atmosphere are presented in Fig. 7. For ASA, its fusion is directly followed by two successive mass losses. The first mass loss is the result of the separation between salicylic acid and acetic acid with a possible formation of $\mathrm{CO}$ and $\mathrm{CO}_{2}$ as observed in our results above. This first loss is most likely accompanied by the formation of previously described ASA polymer [31].The second mass lossis obviously the evaporation/pyrolysis of this polymer.

It is clear from the TG curve of pure TIC that it is much more stable than ASA, as its mass loss only starts around $300{ }^{\circ} \mathrm{C}$, far above its melting temperature. This resistance to high temperature could be explained by the chemical structure of TIC, which consists of a purine nucleoside core, which is known to possess a high thermal resistance [32]. Moreover, other groups are present which can resist high temperatures relatively easily such as the aryl ring, $\mathrm{OH}$, and $\mathrm{NH}$, of which the latter two also form strong intermolecular hydrogen bonds that are difficult to break [33].

Mixtures of $0.3,0.4$, and 0.8 TIC mole fraction were subjected to the TG measurements. It can be seen in Figure 7 that the mass loss patterns of the three mixtures fully fall within the two extremes defined by the behaviour of pure TIC and pure ASA. There does not seem to be any clear evidence of an interaction between ASA and TIC in the mixtures as the curves are to a large extent simply the weighed sum of the curves of the pure compounds. Apparently, the acetyl moiety, which in the stress test appeared to play an important role in the degradation of TIC, does not have the chance to interact with TIC. This may be rather logical when one realises that the boiling point of acetic acid is $118^{\circ} \mathrm{C}$, which implies that the molecule and its derivatives will rapidly evaporate in the TG experiment. This is clearly in contrast to the previous investigations, where the temperature was consistently held below $118^{\circ} \mathrm{C}$. In the case of the TG experiment, acetic acid will form around $100^{\circ} \mathrm{C}$ at the eutectic 
temperature, when a liquid is formed, and subsequently within 2 min the temperature will have reached $120^{\circ} \mathrm{C}$, when the acetic acid will quickly evaporate from the mixture.

Hence, it is clear from the preceding results that the separation of ASA into salicylic acid and acetic acid is at the core of the degradation of TIC, when mixed. This also supports the findings in relation to the reaction rate, which appears to depend mainly on the decomposition of ASA.

Figure 7: Thermogravimetric analysis curves for Ticagrelor, Aspirin and several mixtures under an inert atmosphere

\section{Concluding remarks and pharmaceutical implications of the interactions}

The temperature-composition phase diagram of TIC form II and ASA has been constructed and it has been demonstrated through the eutectic phase diagram and theTammann curve that physical interactions between the two APIs in the solid state in the form of cocrystals seems to beabsent and in the form of solid solutions is probably limited. The solid mixture appears to be stable at room temperature at least for a year, but the formation of acetic acid originating from ASA should be avoided. It has clearly been shown that this is one of the major products that causes the degradation of TIC, when in contact with ASA. LC-HR-MS ${ }^{n}$ characterization of the degradation/interaction products (DPs/IPs) revealed the strong interaction between the donor and acceptor sites of the two APIs. The main mechanism of TIC degradation involved $\mathrm{N}$-dealkylation as demonstrated by the degradation products formed from the interaction products between ASA and TIC.

Although the polypill concept presents many advantages in terms of patient compliance [34], inappropriate manufacturing processes or storage conditions may lead to chemical instability and compromise the drug. For example,even at room temperature, ASA can undergo 
moisture-catalysed hydrolysis [27] and degradation of TIC-ASA mixtures are expected under humid conditions. Moreover, TIC-ASA interactions generate hydrophilic (DPs) and lipophilic (IPs) products, which alter the pharmacokinetics and pharmacodynamics of the drug and hence reduce the potency [35]. Furthermore, ASA induced degradation of TIC generates primary arylaminethrough the $\mathrm{N}$-dealkylation process, which are reported to participatein the metabolic activation by cytochrome P450, which may generate mutagenic and carcinogenic metabolites [36-38].

It has been shown in this paper, that there is a clear interaction between ASA and TIC and how to avoid it, information that can be used for the development of a combination therapy with ASA and TIC. It is clear that scientific research is indispensable to provide relevant information for preformulation strategies and quality risk assessment for the drug life cycle [39-41]

\section{Acknowledgements}

We thank Katia Manerlax and MehrezSghaier (University Paris-Sud) for their contributions to this work and their advice.

\section{References}

[1] Engelmann B, Massberg S. Thrombosis as an intravascular effector of innate immunity. Nat. Rev. Immunol. 13, 34-45 (2013).

[2] Almond HR, Janicki CA Jr. Reaction of Haloperidol with 5 (Hydroxymethyl)-2Furfuraldehyde, an Impurity in Anhydrous Lactose. J. Pharm. Sci. 1974; 63: 41-43.

[3] TischingerH,Wagner et al. Oxidative Degradation of Linoleic Acid Methylester in Suspensions of Inorganic Excipients.Part 1.Pharmazie 42: 320-324. 
[4]Horiuchi S, Ikeda K, Kayashima K, Mizutari K, Ono T. Photo Enhanced Modification of Human Skin Elastin in Actinic Elastosis by $\mathrm{N}$ - (Carboxymethyl)lysine, One of the Glycoxidation Products of the MaillardReaction. J. Inve. Dermatology.1997; 108: 792-802.

[5]Rajewski RA, Stella VJ. Cyclodextrins: their future in drug formulation and delivery. Pharm. Res. 1997; 14: 556-567.

[6] Buckley MM, Benfield P. 1993. Eutectic lidocaine/prilocaine cream. Drugs 46 (1), 126151.

[7] James S, Akerblom A, Cannon CP, et al. Comparison of ticagrelor, the first reversible oral P2Y(12) receptor antagonist, with clopidogrel in patients with acute coronary syndromes: rationale, design, and baseline characteristics of the PLATelet inhibition and patient Outcomes (PLATO) trial. Am Heart J 2009;157(4):599-605

[8] Berger JS, Sallum RH, Katona B, Maya J, Ranganathan G, Xu Y, Mwamburi M. Is there an association between aspirin dosing and cardiac and bleeding events after treatment of acute coronary syndrome? A systematic review of the literature. Am Heart J 2012;164:153162.e5.

[9] Renli T, Juan M, Kathleen B. Evaluation of the pharmacokinetics and pharmacodynamics of ticagrelor co-administered with aspirin in healthy volunteers. Platelets, December 2013; 24(8): 615-624.

[10] Myers RL. The 100 Most Important Chemical Compounds: A Reference Guide. Greenwood Press, 88 Post Road West, Westport, CT 06881. 
[11] Aulton M E, Taylor K. Aulton's Pharmaceutics: The Design and Manufacture of Medicines. Fourth Ed (2013) Churchill Livingstone.

[12] Carstensen JT, Attarchi F. Decomposition of aspirin in the solid state in the presence of limited amounts of moisture II: Kinetics and salting-in of aspirin in aqueous acetic acid solutions. J Pharm Sci. 1988 Apr;77(4):314-7.

[13] BohlinM, Cosgrove S, LassenB.Crystalline and amorphous form of a triazolo(4,5d)pyrimidine compound. 2003, Patent US 20030181469 A1.

[14] SadouYaye H, Secrétan PH, Henriet T, Bernard M, Amrani F, Akrout W, Tilleul P, Yagoubi N, Do B. Identification of the major degradation pathways of ticagrelor. J Pharm Biomed Anal. 2015 Feb;105:74-83.

[15] Kim Y, Machida K, Taga T, Osaki K.Structure redetermination and packing analysis of aspirin crystal.Chem Pharm Bull (Tokyo). 1985 Jul;33(7):2641-7.

[16] Vargha $\mathrm{V}$. Binary solid-liquid phase diagram of the two diastereomerracemates of triglycidylisocyanurate (TGIC). European Polymer Journal, Volume 43, Issue 11, November 2007, Pages 4762-4769.

[17] Herman C, Haut B, Aerts L, Leyssens T, 2012. Solid-liquid phase diagrams for the determination of the solid state nature of both polymorphs of (RS)-2-(2- oxo-pyrrolidin-1-yl)butyramide. Int. J. Pharm. 437, 156-161.

[18] Diarce G, Gandarias I, Campos-Celador Á, García-Romero A, Griesser UJ. Eutectic mixtures of sugar alcohols for thermal energy storage in the $50-90{ }^{\circ} \mathrm{C}$ temperature range. Solar Energy Materials and Solar Cells, Volume 134, March (2015) 215-226. 
[19] Guenet JM. Contributions of phase diagrams to the understanding of organized polymersolvent systems. ThermochimActa. 1996;284:67-83.

[20] Rycerz L. Practical remarks concerning phase diagrams determination on the basis of differential scanning calorimetry measurements. Journal of Thermal Analysis and Calorimetry, July 2013, Volume 113, Issue 1, pp 231-238.

[21] Goldberg AH, Gibaldi M, Kanig JL. Increasing dissolution rates and gastrointestinal absorption of drugs via solid solutions and eutectic mixtures. I. Theoretical considerations and discussion of the literature. J Pharm Sci. 1965 Aug;54(8):1145-8.

[22] Bi M, Hwang S.-J, Morris KR. Mechanism of eutectic formation upon compaction and its effects on tablet properties. Thermochim.Acta, 2003, 404, 213.

[23] Law D, Wang W, Schmitt EA, Qiu Y, Krill SL, Fort JJ. Properties of Rapidly Dissolving Eutectic Mixtures of Poly(ethylene glycol) and Fenofibrate: The Eutectic Microstructure. J. Pharm. Sci., 2003, 92, 505.

[24] Singh NB, Das SS, Singh NP, Agrawal T. Computer simulation, thermodynamic and microstructural studies of benzamide-benzoic acid eutectic system. J. Cryst. Growth, 2008, 310, 2878.

[25] Moore MD, Wildfong PLD. Aqueous Solubility Enhancement Through Engineering of Binary Solid Composites: Pharmaceutical Applications. J. Pharm. Innovation, 2009, 4, 36.

[26] Jain H, Khomane KS, Bansal AK. Implication of microstructure on the mechanical behaviour of an aspirin-paracetamol eutectic mixture.CrystEngComm, 2014,16, 8471.

[27] Carstensen JT, Attarchi F. Decomposition of aspirin in the solid state in the presence of limited amounts of moisture III: Effect of temperature and a possible mechanism.JPharm Sci. 1988 Apr;77(4):318-21. 
[28] Mackie JC, Doolan KR. High-temperature kinetics of thermal decomposition of acetic acid and its products. Int Journal of Chemical Kinetics, Vol 16, Issue 5, May 1984, Pages 525-541.

[29] Ju Young Parkln Hwa Lee. Decomposition of acetic acid by advanced oxidation processes,Korean Journal of Chemical Engineering, March 2009, Volume 26, Issue 2, pp 387-391.

[30] Yoshioka S, Aso Y. Correlations between molecular mobility and chemical stability during storage of amorphous pharmaceuticals. J Pharm Sci. 2007 May;96(5):960-81.

[31] Silva EMA, Melo DMA, Moura MFV, Farias RF. An investigation about the solid state thermal degradation of acetylsalicylic acid: polymer formation, Thermochim. Acta 414 (2004) 101-104.

[32] Wang XJ, You JZ. Study on the molecular structure and thermal stability of purine nucleoside analogs. Journal of Analytical and Applied Pyrolysis, Volume 111, January 2015, Pages 1-14.

[33] Nadia A. Mohamed, Nahed A. Abd El-Ghany, Mona M. Fahmy. Thermogravimetric analysis in the evaluation of the inhibition of degradation of rigid poly(vinyl chloride) using biologically active phthalimido aromatic hydrazide derivatives. Polymer Degradation and Stability, Volume 128, June 2016, Pages 46-54.

[34] Wiley B, Fuster V. The concept of the polypill in the prevention of cardiovascular disease.Ann Glob Health. 2014 Jan-Feb;80(1):24-34. 
[35] Springthorpe B, Bailey A, Barton P, Birkinshaw TN, Bonnert RV, Brown RC, Chapman D, Dixon J, Guile SD, Humphries RG, Hunt SF, Ince F, Ingall AH, Kirk IP, Leeson PD, Leff P, Lewis RJ, Martin BP, McGinnity DF, Mortimore MP, Paine SW, Pairaudeau G, Patel A, Rigby AJ, Riley RJ, Teobald BJ, Tomlinson W, Webborn PJ, Willis PA. From ATP to AZD6140: the discovery of an orally active reversible $\mathrm{P} 2 \mathrm{Y} 12$ receptor antagonist for the prevention of thrombosis. Bioorg Med Chem Lett. 2007 Nov 1;17(21):6013-8. Epub 2007 Aug 19.

[36] WoganGN, Hecht SS, Felton JS, ConneyAH, Loeb LA. Environmental and chemical carcinogenesis.Seminars in Cancer Biology 14 (2004) 473-486 [2] Robert J. Turesky.Heterocyclic aromatic amines.Advances in Molecular Toxicology, Volume 4.

[37] TureskyRJ, Constable A, RichozJ, VargaN, MarkovicJ, Martin MV, GuengerichFP. Activation of heterocyclic aromatic amines by rat and human liver microsomes and by purified rat and human cytochrome P450 1A2, Chem. Res. Toxicol. 11 (1998) 925-936.

[38] Benigni, R., Giuliani, A., Franke, R., and Gruska, A. (2000). Quantitative structureactivity relationships of mutagenic and carcinogenic aromatic amines.Chem.Revs. 100, 3697-3714.

[39] ICH, Stability Testing Of New Drug Substances and Products Q1A (R2) Current Step 4 version dated 6 February 2003.

[40] ICH, Pharmaceutical Development Q8 (R2) Current Step 4 version dated August 2009.

[41] ICH, Quality Risk Management Q9, Current Step 4 version dated 9 November 2005. 
Table 1

\begin{tabular}{|c|c|c|c|c|c|c|}
\hline Compounds & $25^{\circ} \mathrm{C}$ & $80^{\circ} \mathrm{C}(\mathrm{D} 1)$ & $80^{\circ} \mathrm{C}(\mathrm{D} 3)$ & $100{ }^{\circ} \mathrm{C}(\mathrm{D} 1)$ & $100{ }^{\circ} \mathrm{C}(\mathrm{D} 3)$ & $\begin{array}{l}\text { Under light (1.5 } \\
\text { W/m2) (D3) }\end{array}$ \\
\hline TIC & $\begin{array}{l}\text { White } \\
\text { powder }\end{array}$ & $\begin{array}{l}\text { White } \\
\text { powder }\end{array}$ & $\begin{array}{l}\text { White } \\
\text { powder }\end{array}$ & $\begin{array}{l}\text { White } \\
\text { powder }\end{array}$ & $\begin{array}{l}\text { White } \\
\text { powder }\end{array}$ & White powder \\
\hline ASA & $\begin{array}{l}\text { White } \\
\text { powder }\end{array}$ & $\begin{array}{l}\text { White } \\
\text { powder }\end{array}$ & $\begin{array}{l}\text { White } \\
\text { powder }\end{array}$ & $\begin{array}{l}\text { White } \\
\text { powder }\end{array}$ & $\begin{array}{l}\text { White } \\
\text { powder }\end{array}$ & White powder \\
\hline TIC-ASA (w:w) & Whitepowder & Whitepowder & $\begin{array}{l}\text { Melted and } \\
\text { yellownish }\end{array}$ & $\begin{array}{l}\text { Melted and } \\
\text { yellownish }\end{array}$ & $\begin{array}{l}\text { Melted and } \\
\text { yellownish }\end{array}$ & Whitepowder \\
\hline
\end{tabular}


Table2

TIC-ASA interactions products

\begin{tabular}{ccccc}
\hline $\begin{array}{c}\text { Interaction } \\
\text { products }\end{array}$ & $\begin{array}{c}\text { Retention } \\
\text { time (min) }\end{array}$ & $\begin{array}{c}\text { Accurate } \\
\text { mass }\end{array}$ & $\begin{array}{c}\text { Exact } \\
\text { mass }\end{array}$ & $\begin{array}{c}\text { Error } \\
(\mathbf{p p m})\end{array}$ \\
\hline TIC API & 11.05 & 523.1819 & 523.1816 & 0.6 \\
& & & & \\
\hline $\begin{array}{c}\text { Carbonmonoxide- } \\
\text { TIC }\end{array}$ & 13.27 & 551.1857 & 551.1883 & -4.7 \\
(IP1) & & 533.1766 & 533.1778 & -2.3 \\
& & 523.1820 & 523.1816 & 0.7 \\
& & 505.1707 & 505.1731 & -4.8 \\
& & 399.1433 & 399.1445 & -2.9 \\
& & 391.1167 & 391.1147 & 5.1 \\
& & 363.1094 & 363.108 & 3.9
\end{tabular}

Correspondent TIC N-dealkylation degradation products

\begin{tabular}{|c|c|c|c|c|}
\hline Degradationproducts & $\begin{array}{l}\text { Retention } \\
\text { time (min) }\end{array}$ & $\begin{array}{c}\text { Accurate } \\
\text { mass }\end{array}$ & $\begin{array}{l}\text { Exact } \\
\text { mass }\end{array}$ & $\begin{array}{l}\text { Error } \\
\text { (ppm) }\end{array}$ \\
\hline \multirow[t]{3}{*}{371} & 8.35 & 371.1488 & 371.1502 & -3.8 \\
\hline & & 343.1433 & 343.1429 & 1.2 \\
\hline & & 325.1332 & 325.1323 & 2.8 \\
\hline $371-\mathrm{CO}$ & 8.96 & 399.1429 & 399.1445 & -4.0 \\
\hline \multirow[t]{9}{*}{ (DP1) } & & 381.1324 & 381.134 & -4.2 \\
\hline & & 371.1492 & 371.1496 & -1.1 \\
\hline & & 371.1372 & 371.1384 & -3.2 \\
\hline & & 357.0973 & 357.0976 & -0.8 \\
\hline & & 337.1092 & 337.1077 & 4.4 \\
\hline & & 329.1022 & 329.1027 & -1.5 \\
\hline & & 329.0910 & 329.0914 & -1.2 \\
\hline & & 311.0807 & 311.0809 & -0.6 \\
\hline & & 169.0176 & 169.0179 & -1.8 \\
\hline $371-\mathrm{COCH}_{2}$ & 8.56-8.78- & 1121507 & 4131602 & -36 \\
\hline (DP2) & & 371.1487 & 371.1502 & -3.9 \\
\hline $371-\left(\mathrm{COCH}_{2}\right)_{2}$ & $\begin{array}{c}9.19-9.49- \\
9.72\end{array}$ & 455.1689 & 455.1707 & -4.0 \\
\hline \multirow[t]{2}{*}{ (DP3) } & & 413.1595 & 413.1602 & -1.8 \\
\hline & & 371.1494 & 371.1496 & -0.5 \\
\hline $371-\left(\mathrm{COCH}_{2}\right)_{3}$ & $9.85-10.88$ & 497.1791 & 497.1812 & -4.2 \\
\hline \multirow[t]{3}{*}{ (DP4) } & & 455.1696 & 455.1707 & 0.0 \\
\hline & & 413.1595 & 413.1602 & -1.7 \\
\hline & & 371.1488 & 371.1502 & -3.9 \\
\hline 371-Salicylate & 10.51 & 491.1697 & 491.1707 & -2.0 \\
\hline \multirow[t]{2}{*}{ (DP5) } & & 371.1488 & 371.1502 & -3.8 \\
\hline & $\begin{array}{c}9.96-11.27- \\
12.18\end{array}$ & 533.1790 & 533.1813 & -4.3 \\
\hline \multirow[t]{2}{*}{ (DP6) } & & 413.1592 & 413.1602 & -2.4 \\
\hline & & 371.1491 & 371.1502 & -3.0 \\
\hline
\end{tabular}


Diacetyl-TIC-

Salicylate

(IP7)
20.77-21.16-

21.8

$607.2134 \quad 607.2145$

$565.2033 \quad 565.2039$
10.17-

10.65-

$11.30 \quad 575.1888 \quad 575.1919 \quad-5.4$

Salicylate

$533.1798 \quad 533.1813$

$-2.8$

(DP7)

$491.1706 \quad 491.1707$

$-0.2$

$413.1591 \quad 413.1602$ 

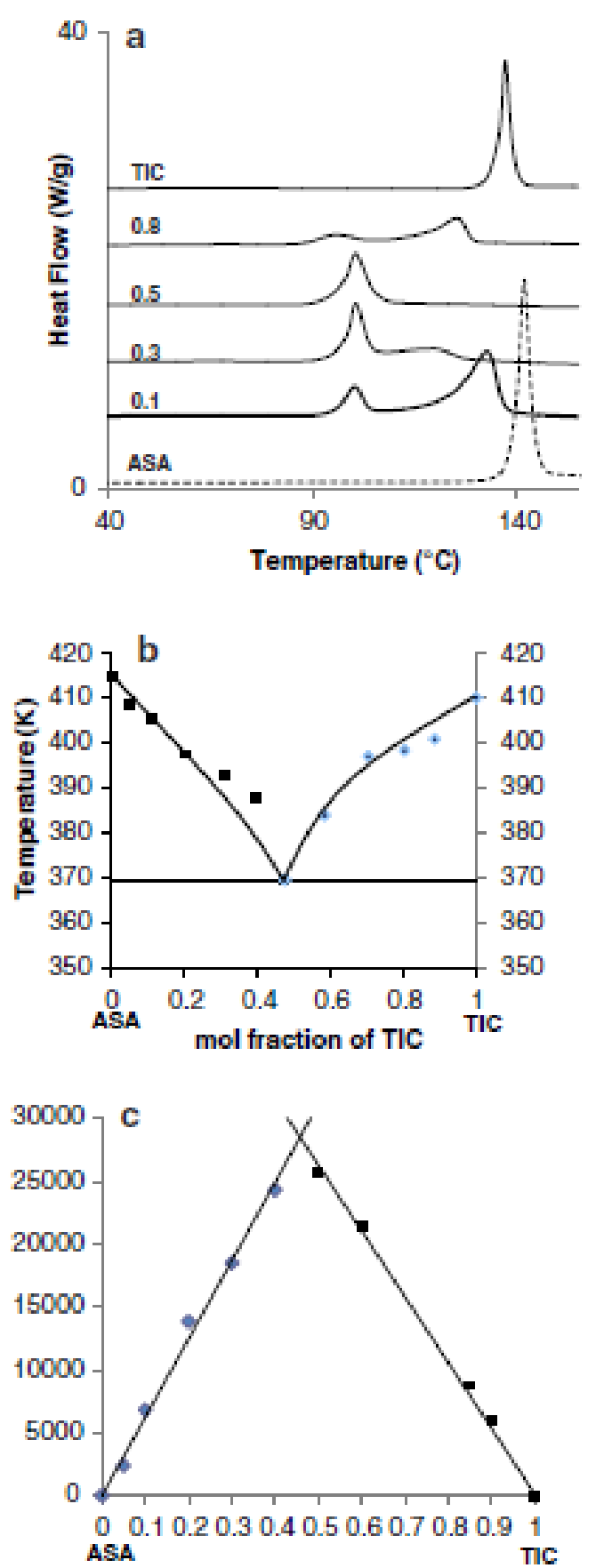

Figure 1 

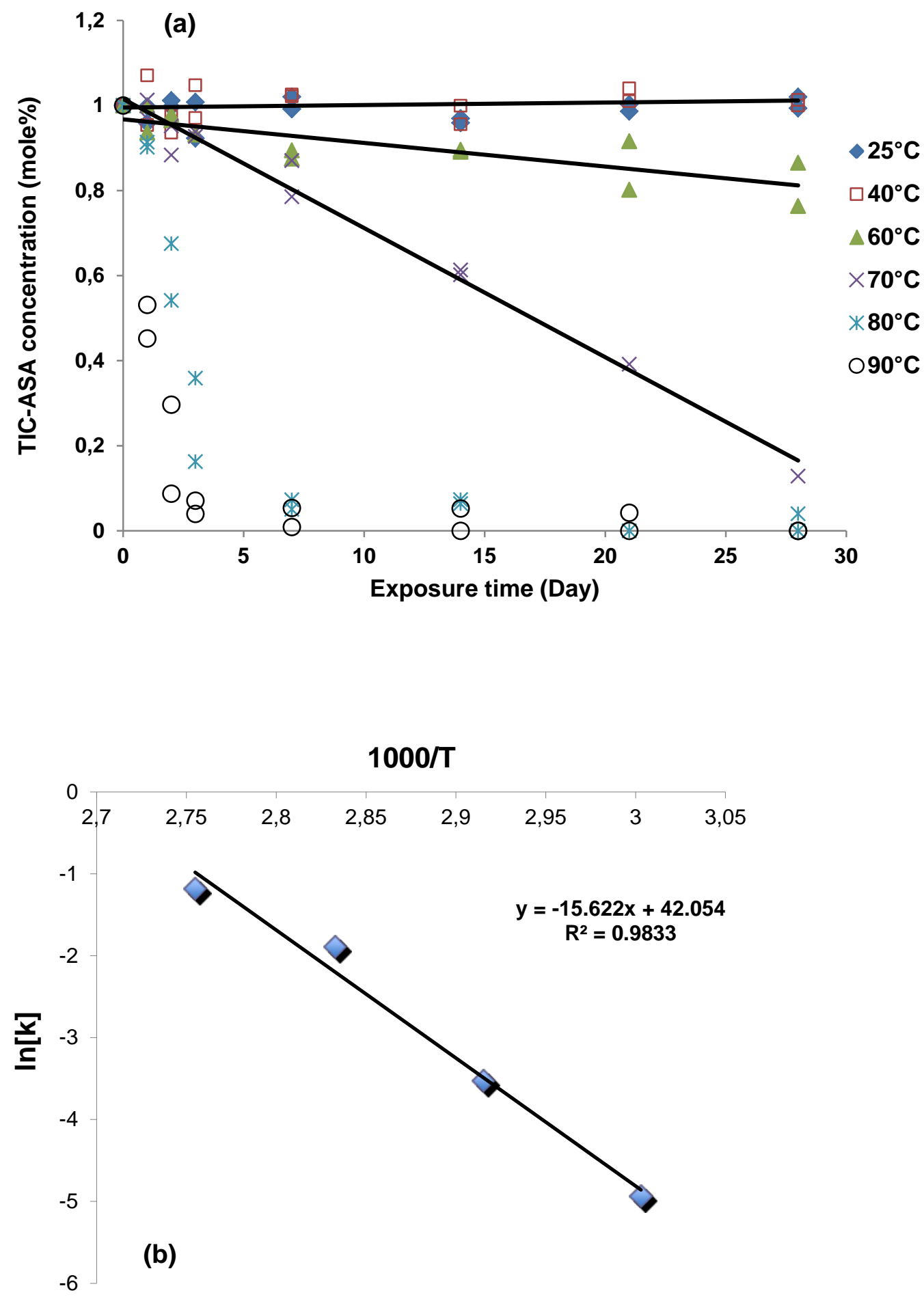

Figure 2 

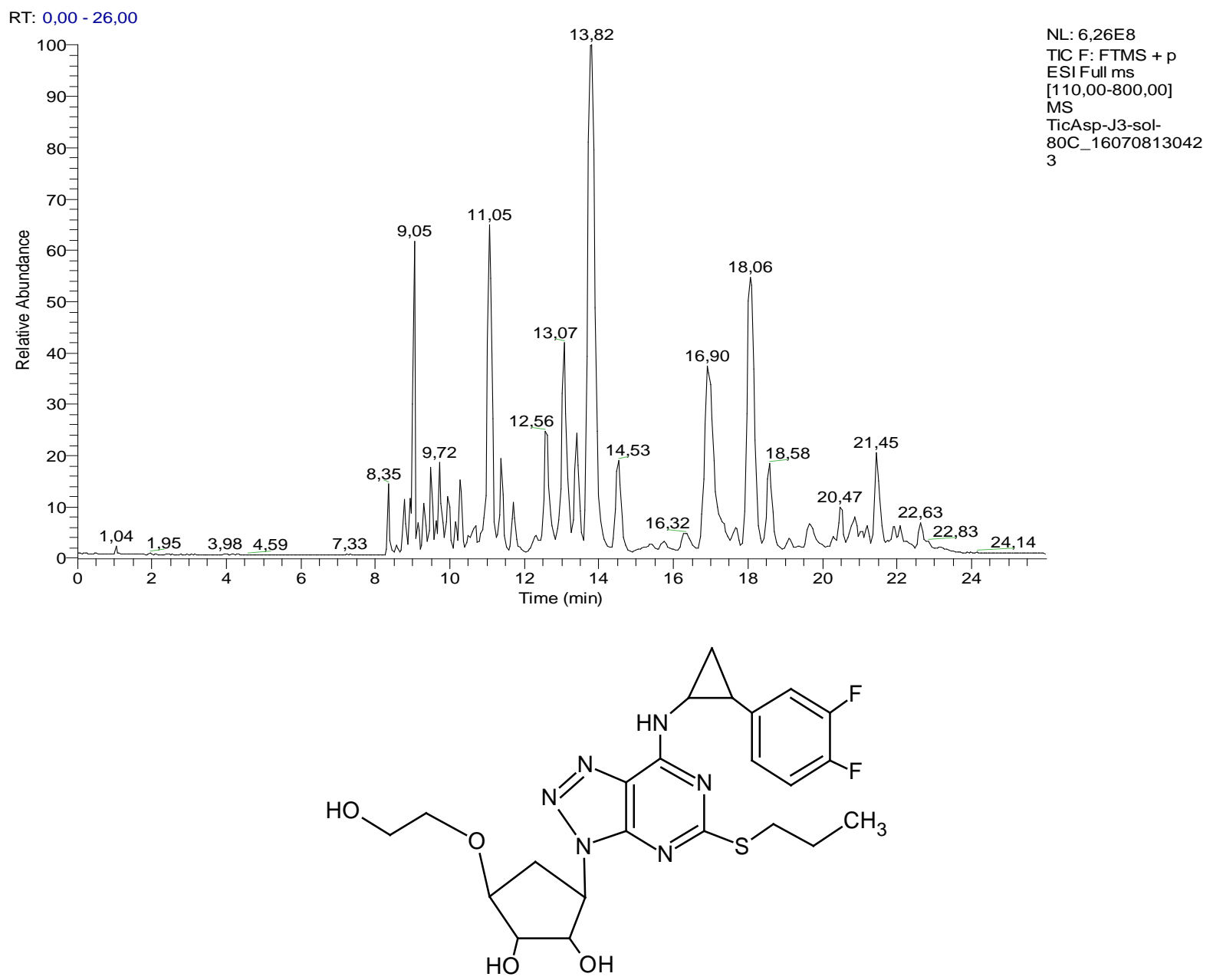

Figure 3 


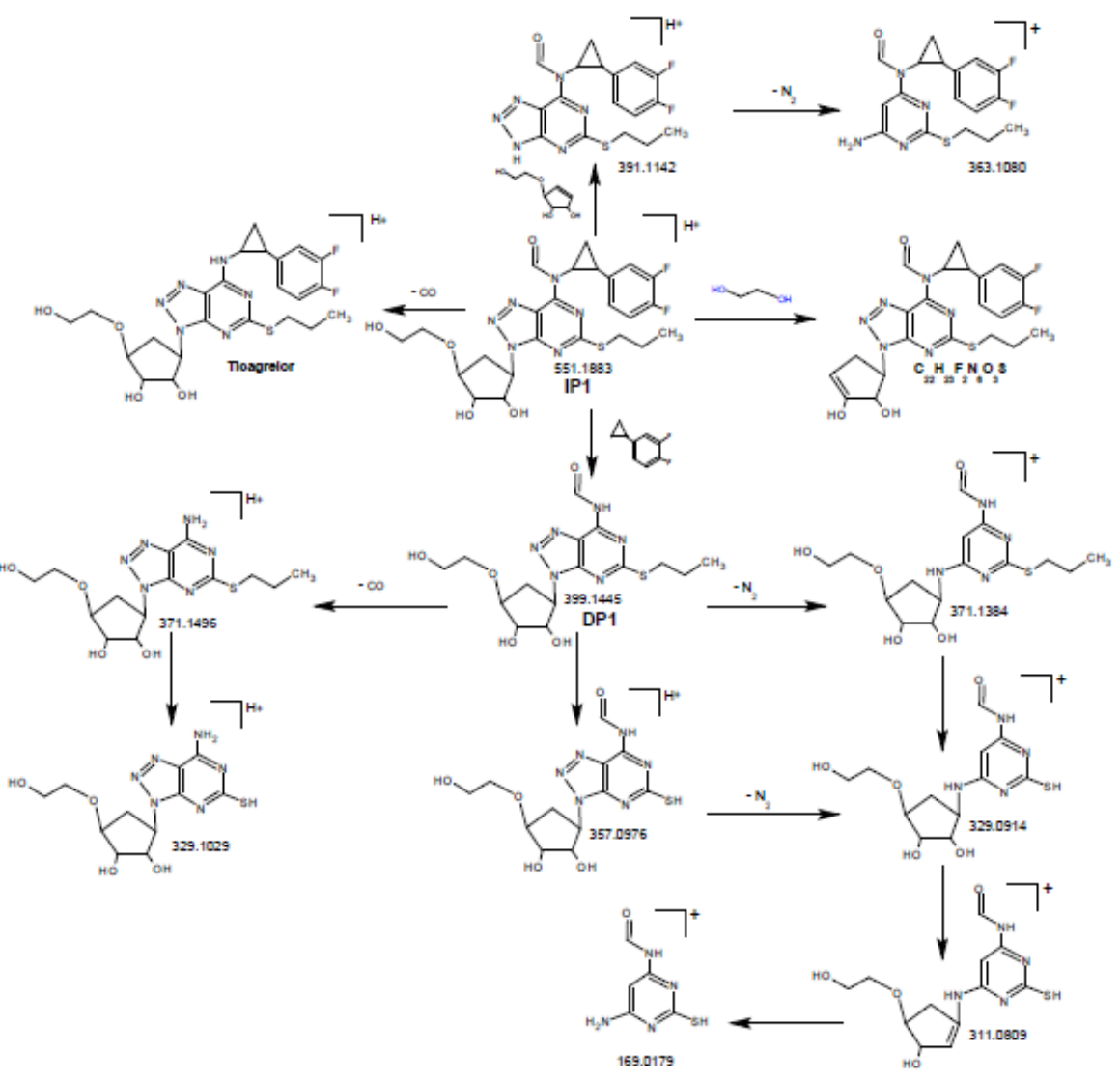

Figure 4 

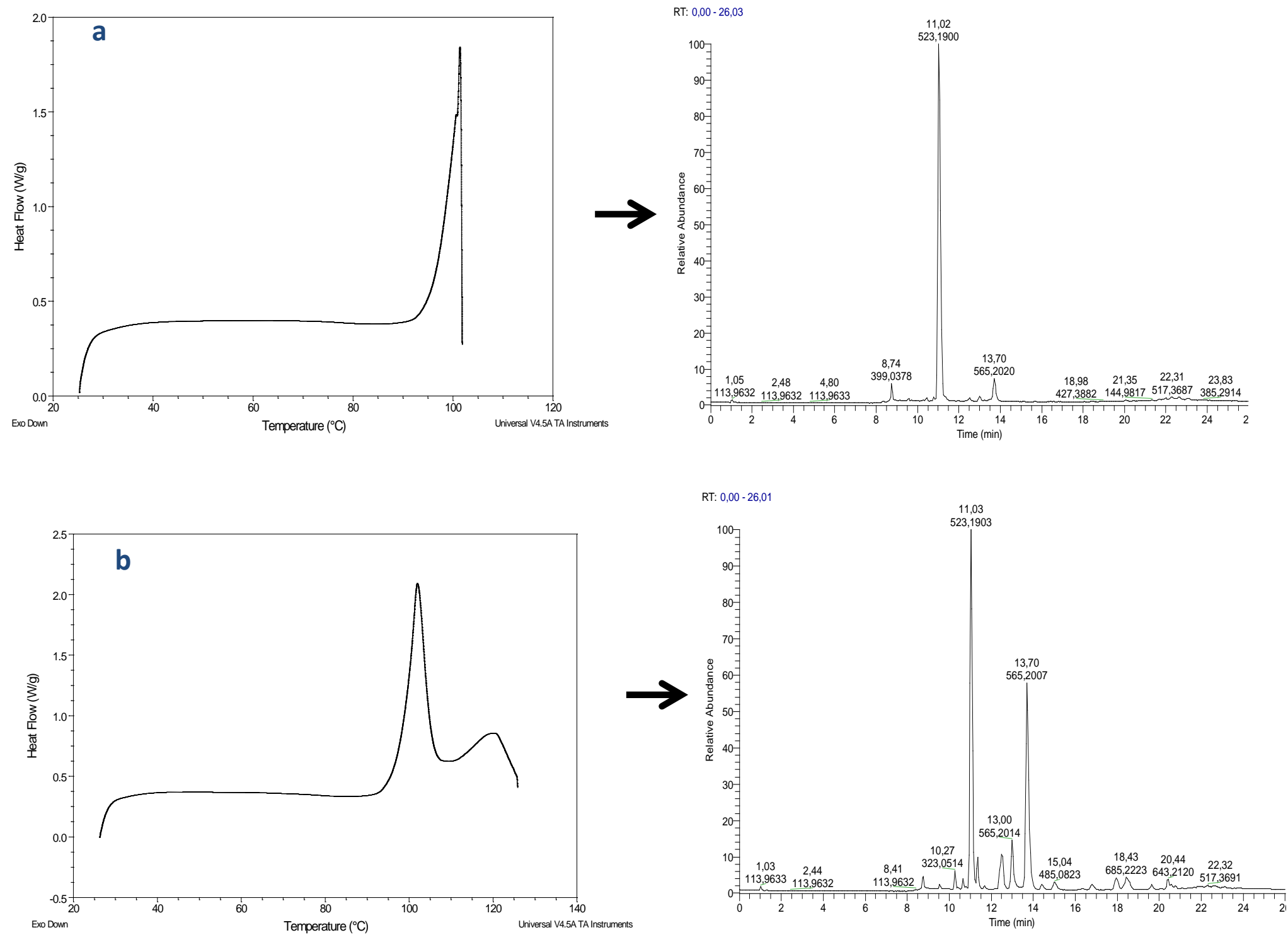

Figure 5 


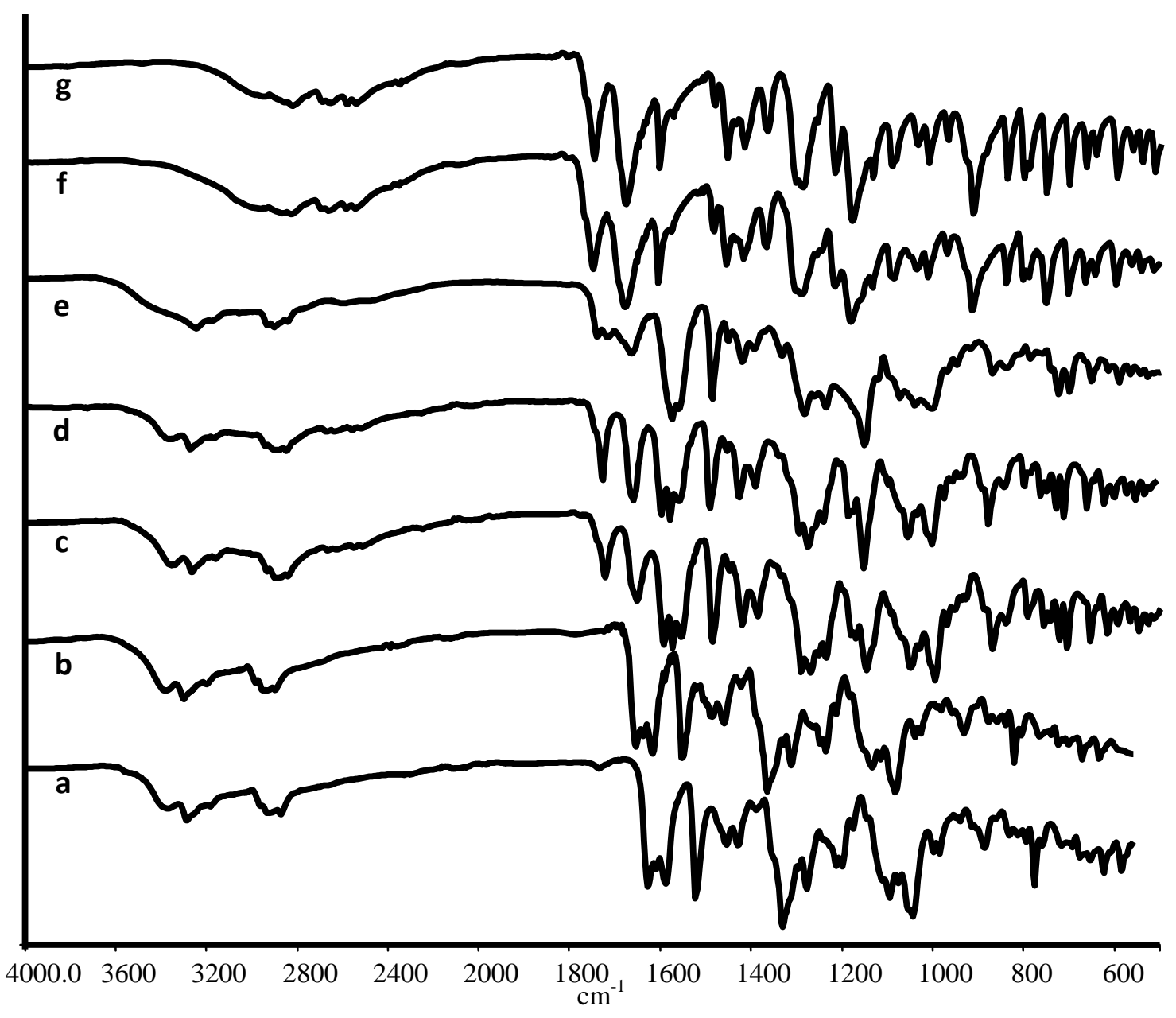

Figure 6 


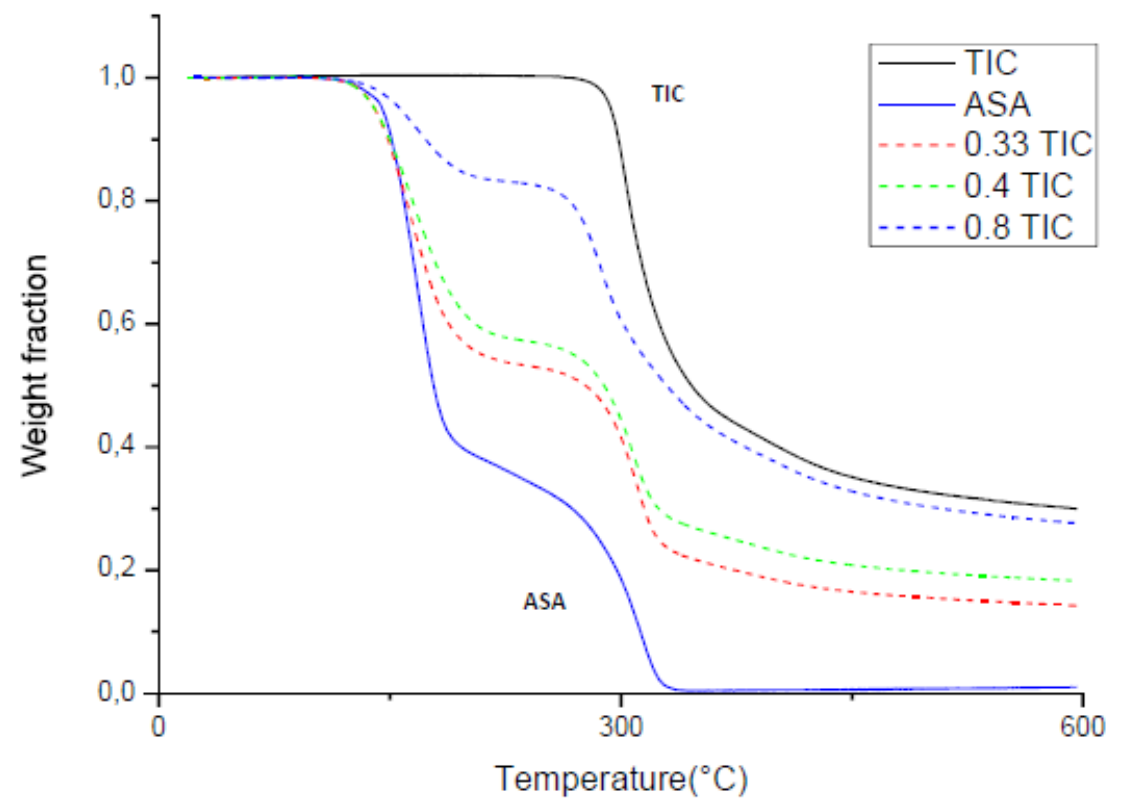

Figure 7 